Cómo citar este artículo en Chicago: Pérez Bernal, Ángeles M. a del Rosario. "El amor como "aventura solitaria" en Hedwig and the Angry Inch, de John Cameron Mitchell”. Escritos 30, no. 64 (2022): 136-148.

doi: http://doi.org/10.18566/escr.v30n64.a08

Fecha de recepción: 29.07 .2021

Fecha de aceptación: 13.12 .2021

\title{
El amor como "aventura solitaria" en Hedwig and the Angry Inch, de John Cameron Mitchell
}

\author{
Love as a "lonely adventure" in Hedwig and the Angry Inch, \\ by John Cameron Mitchell
}

\author{
Ángeles M. del Rosario Pérez Bernal ${ }^{1}$
}

\begin{abstract}
RESUMEN
Indudablemente, la película Hedwig and the Angry Inch establece un diálogo con la tesis del amor expuesta por Diotima de Mantinea en El Banquete de Platón, en el sentido de entender el amor como una aventura solitaria y de expansión primordialmente individual. Sin embargo, la película más que transvasar las ideas del filósofo griego, abre una discusión sobre su vigencia y actualidad en situaciones concretas como la identidad, la ideología y el género. Es por esto que en el filme la anagnórisis se convierte en anamnesis; la dialéctica es un agón, y la identidad, un devenir.
\end{abstract}

Palabras clave: Concepto platónico del amor; Diotima de Mantinea; Hedwig and the Angry Inch (película); John Cameron Mitchell (director); Anagnórisis; Dialéctica; Identidad; Devenir.

\begin{abstract}
Undoubtedly, the film Hedwig and the Angry Inch establishes a dialogue with the thesis of love exposed by Diotima of Mantinea in Plato's Banquet, in the sense of understanding love as a solitary adventure and primarily individual expansion. However, more than transferring the ideas of the Greek philosopher, the film opens a discussion about its validity and topicality in specific situations such as identity, ideology and gender. This is why anagnorisis becomes anamnesis in the film; dialectics is an agon, and identity, a becoming.
\end{abstract}

Keywords: Platonic Concept of Love; Diotima of Mantinea; Hedwig and the Angry Inch (film); John Cameron Mitchell (director); Anagnorisis; Dialectic; Identity; Becoming.

1 Posdoctorado en la Universidad de París I Pantheon Sorbonne, Francia. Doctora en Estudios Latinoamericanos por la Universidad Nacional Autónoma de México. Profesora-investigadora en la Universidad Autónoma del Estado de México. Correo electrónico: rosarioperezbernal7@gmail.com 


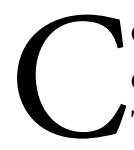

omo road movie, el filme cuyo estreno fue en 2001, Hedwig and the Angry Inch nos introduce en el viaje que una banda de rock realiza por los Estados Unidos en su persecución de la estrella Tommy Gnosis; la banda, encabezada por Hedwig, mujer transgénero perteneciente al este de Alemania, estará a la sombra de unas circunstancias cuyo telón de fondo son el célebre texto de Platón, El banquete.

Este evidente trasfondo platónico es el eje donde discurren todas las circunstancias más relevantes en la vida de Hedwig. Sometida a una operación de cambio de sexo (que le permitiría casarse con un soldado norteamericano), Hedwig ve con terror que el resultado de dicha operación es haber quedado con una "pulgada furiosa". Ni hombre ni mujer por entero, Hedwig pasa en un instante por este cambio y un abandono. Sola ya en Kansas, se moldeará a sí misma como una drag queen, una estrella del rock que ha sido fulminada por la presencia de Eros en su vida. En el punto donde comienza el argumento del filme, esta presencia tendrá el nombre específico de Tommy Gnosis, un antiguo discípulo y protegido de ella que no solo le robó sus canciones y su poder creativo, sino que la dejó herida de amor.

Así pues, El banquete, de Platón, será un reflejo constante de este viaje. Dadas las circunstancias, podría creerse que el largometraje solo se mira en el espejo del mito del andrógino que cuenta Aristófanes en el texto de Platón. Pero, como ocurre con El banquete, la participación de Aristófanes abre espacio a un discurso sobre Eros mucho más potente: el de Sócrates. Pero el propio Sócrates es un discípulo, el discurso al que asistimos está en la extraña voz de una sacerdotisa: Diótima de Mantinea.

\section{El mito del andrógino y el origen del amor para Hedwig}

De entre las numerosas obras de Platón, El banquete es, quizá, uno de los textos más entrañables en el pensamiento occidental, no solo en el obligado aspecto filosófico, sino en una extensión de su pensamiento en el sustrato cotidiano de sociedades tan variadas como dispares en el tiempo y geografía, destino que pocos artistas, filósofos u obras comparten. Lo anterior vale para decir algo equiparable con Shakespeare, no significa que algún mercader del siglo XVIII haya leído al vate inglés, pero su imaginario personal, familiar e, incluso, metafísico ha de ser un campo de lenguaje producto de Hamlet (personaje), Rosalinda, Macbeth, Yago o Lear. De la misma manera, un ingeniero o médico cualquiera del siglo XXI difícilmente habrá leído en su cabalidad El banquete, de Platón; no obstante, quizá, haya tenido en sus angustias eróticas y sensuales el trasfondo de las concepciones discutidas entre Agatón, Aristófanes, Erixímaco, Sócrates y compañía. Sus imágenes de mundo ${ }^{2}$ acaso estén pobladas de los ejes axiomáticos que presenta Platón; la tríada inseparable entre lo verdadero, lo bueno y lo bello, la idea de la belleza en sí o el mito del andrógino que presenta Aristófanes en el coloquio... Parte del hechizo (si dejamos de lado la composición dramática, el aura que rodea la figura de Sócrates y su encubierta, pero insistente apología que introduce Platón cada que tiene oportunidad) reside en la potencia de sus mitos capaces de dar forma a toda una realidad compleja y variada.

En ese sentido, compiten el mito de la caverna y el mito del andrógino. Pero dicho lo anterior, es evidente que existe una distancia enorme entre el mito del andrógino y la forma vulgar de la idea de la "otra mitad" en el amor, de la cual han sacado provecho un amplísimo catálogo de canciones, así como el cine

2 Véase Martin Heidegger, “La época de la imagen del mundo”, en Caminos de bosque (Madrid: Alianza, 1996). 
más popular. No sería extraño encontrarnos la Vulgata de la enseñanza de Platón en manos torpes e inhábiles, pero tampoco sería de extrañar hallar un discurso articulado en el campo de la cultura actual por estas mismas representaciones. Según la postura expuesta, Hedwig and the Angry Inch haría una revisión moderna a dos momentos cumbres de El banquete e, incluso, copiaría su estructura a través de una road movie.

En primer término, está la revisión del mito del andrógino que expone Aristófanes cuando le llega el turno para hablar de eros:

En primer lugar, tres eran los sexos de las personas, no dos, como ahora, masculino y femenino, sino que había, además, un tercero que participaba de estos dos, cuyo nombre sobrevive todavía, aunque él mismo ha desaparecido. El andrógino, en efecto, era entonces una cosa sola en cuanto a forma y nombre, que participaba de uno y de otro, de lo masculino y de lo femenino, pero que ahora no es sino un nombre que yace en la ignominia. En segundo lugar, la forma de cada persona era redonda en su totalidad, con la espalda y los costados en forma de círculo. Tenía cuatro manos, mismo número de pies que de manos y dos rostros perfectamente iguales sobre un cuello circular. Y sobre estos dos rostros, situados en direcciones opuestas, una sola cabeza, y además cuatro orejas, dos órganos sexuales, y todo lo demás como uno puede imaginarse a tenor de lo dicho. ${ }^{3}$

En la descripción de estos acontecimientos, Platón hace decir a Aristófanes que estos seres representaron un peligro para Zeus y los demás dioses. Tanto los hijos del Sol (hombre-hombre) como los de la Tierra (mujer-mujer) e, incluso, los de la Luna (hombre-mujer) conspiraron contra los dioses; en consecuencia, estos deliberaron cortar a aquellos por la mitad. Esto los hacía más débiles y dóciles. La consecuencia resulta evidente: originariamente, el ser humano tuvo una doble naturaleza, hubo alguien con quien formamos unidad.

Bajo esta concepción, Hedwig mantiene toda una idea del amor completamente dependiente del hecho de que cree ser un ente incompleto (sema que se refuerza con su condición en el tema de sus genitales mutilados). La canción The Origin of Love es casi un calco del mito platónico del andrógino, con el agregado diferencial que hace partícipes del mito a deidades y discursos míticos completamente anacrónicos como Thor, Osiris y el "dios indio".

Sin embargo, ¿cuál es el origen del amor para Hedwig? La película nunca se centra explícitamente en este punto, pero es significativo entender la historia de Hedwig como la relación repetida de un abuso: primero su padre, luego Luther y finalmente Tommy Gnosis. Pau Gilabert Barberá sugiere ${ }^{4}$ que la incorporación del mito del andrógino por Hedwig sería una idealización del amor. Idealización frente a realidad, el mito del andrógino frente al conocimiento verdadero del amor, el discurso de Aristófanes contra el de Diótima-Sócrates.

3 Platón, Diálogos, trad. por Carlos García Gual, Marcos Martínez Hernández y Emilio Lledó Íñigo (Madrid: Gredos, 1986), 222.

4 Pau Gilabert Barberà, "Hedwig and the Angry Inch: El Platón más alternativo", Actas del XI Congreso Español de Estudios Clásicos 3 (2005): 679-690, http://diposit.ub.edu/dspace/handle/2445/12165 
Habría que agregar que se trata, incluso, de una defensa, de todo un aparato ideológico autoimpuesto para poder explicar los eventos a los que Hansel-Hedwig se ve arrojado y arrojada a lo largo de la película. Sin embargo, el encanto particular de esta road movie consiste en un viaje que llega a un punto nuevo; Hedwig crea algo a pesar de todo, y la apuesta de la película es sumamente moderna: el maestro es discípulo y el discípulo maestro.

\section{El amor homosexual de un adulto y un joven con fines educativos}

El tema de la pederastia es un asunto que muchos autores han revisado en el aparato argumental de El banquete. Por ejemplo, Laura Alejandra Carrillo Osorio nota que el discurso de Pausanias sobre el tema carece de un hilo conductor realmente veraz, cuando hay un salto de su elogio a Eros cuya mayor virtud es mantener una sociedad fuerte y unificada a través de Afrodita Urania. La pederastia posee una apología en voz de Pausanias que socava la idea misma de la virtud presente en esta Afrodita celeste en tanto se focaliza y da exclusividad a la relación hombre adulto y mancebo dada una supuesta sinceridad en la búsqueda de la virtud. No obstante, Carrillo Osorio conviene:

Si pensamos el discurso de Pausanias sin los jóvenes ingenuos que deben conceder favores a sus amantes para hacerse mejores en la campo de la virtud, podemos imaginar personas que tienen algunos maestros, aprenden de ellos y obtienen un beneficio intelectual, útil y genuino para contribuir con la solidez de la polis. ${ }^{5}$

Dicho de otro modo, el discurso de Pausanias vuelve a caer en el error de sostener la búsqueda de la virtud en el camino del amor a través de elementos transitorios y accidentales como la juventud de los mancebos griegos. Bajo esta perspectiva, la película que nos ocupa repite esa travesía, pero, digamos, a la inversa. Hedwig se ancla en la presencia de Tommy Gnosis no solo por la demanda que planea para recuperar la autoría de sus canciones (resulta muy evidente que Hedwig no puede evitar amar a Tommy, no ya en el fulgor de la belleza en sí que descubrieron a través de la música, sino en el sentido más elemental, obsesión luego de un rechazo turbio -la escena donde Tommy conoce la "pulgada furiosa" de Hedwig-). Esta lectura habría que unirla a la de Alcibíades al final de El banquete, pero para eso es necesario hacer un pasaje sobre este sistema de maestro-discípulo que plantea la película como subtexto, pero también el propio diálogo de Platón y su relación con Sócrates.

\section{De maestros y discípulos}

Desmitificado el origen del amor para Hedwig, toca el turno ahora sobre su relación con los maestros, la gnosis que habrá dado como seña característica de Tommy una vez pudo contemplar la madurez creativa. Es en el primer cuarto de la película cuando Hedwig nos cuenta su experiencia:

5 Laura Alejandra Carrillo Osorio, "El discurso de Pausanias en El banquete y la discontinuidad argumentativa entre Eros, pederastia y sociedad”, Saga: Revista de Estudiantes de Filosofía 15, no. 27 (2016): 34. 
Late at night. I would listen to the voices of the American masters. Tony Tennille, Debby Boone, Anne Murray who was actually a Canadian working in the American idiom. And then there were the cryptohomo rockers: Lou Reed, Iggy Pop, David Bowie who was actually an idiom working in America and Canada. These artists, they left as deep an impression on me as that oven rack did on my face. To be an American in muskrat love, soft as an easy chair not even the chair, I am I said, have I never been mellow? And the colored girls sing... doo do doo do doo do doo... but never with the melody. How could I do it better than Tony or Lou... HEY BOY, TAKE A WALK ON THE WILD SIDE! ${ }^{6}$

No se trata solo del discurso en voz de Hedwig, sino de la forma, su presentación a través de la cámara. Es Hedwig de niño, pero también como mujer, quien dentro de un horno escucha a los grandes maestros del rock norteamericano. No es accidental que se trate de un horno y la cámara dé vueltas: al ser John Cameron Mitchell de habla inglesa, la expresión "A bun is in the oven" le ha de resultar familiar en tanto refiera al hecho de un embarazo. El sutil eje semántico le otorga interioridad a Hedwig, la voz sosegada que relata el hecho dista mucho de la fuerza histriónica en otros momentos de la película. En otras palabras, Hedwig se siente completa dentro de la madre, pero esto no tendría justificación si no se viera afectado por el hecho de que es un ser ya independiente, un ser que reencuentra en la relación maestro-discípulo una conexión más alta con el eros. La poiesis es el aprendizaje que torna a Hedwig en una discípula destacada del rock, la hace avanzar en dos momentos cumbres: su infancia y luego de que es abandonada por Luther. La película ahonda en este alejamiento y reencuentro con la poiesis, porque es evidente y hasta un lugar común decir que el viaje de Hedwig la hace reencontrarse como un ser completo. Sí, por supuesto, sin embargo, el hecho a destacar es cómo el discurso de Platón en El banquete encuentra una potencia y una versión propia en voz de Mitchell.

Mitchell es un discípulo, ha aprendido de Platón y lo va a mostrar no solo con el contenido explícito de la película, sino también con la factura misma de su presentación. Es, en otras palabras, una relectura creativa, acaso porque Mitchell ha entendido bien la presentación de El banquete: la narración no es directa, nunca lo es, incluso, lo que comenta Sócrates solo es la enseñanza de Diótima; el diálogo tampoco es tal, se trata de un debate sobre un tema específico: el amor. Más que diálogo, tenemos la puesta en escena de un agón de discursos y concepciones. El esquema es muy básico, pero, a la vez, realmente original: Diótima instruye a Sócrates, este al resto de los participantes del banquete, uno de ellos, Aristodemo, a Apolodoro, y así hasta Platón, que le toca instruir a los lectores de sus diálogos. Todo esto tiene la estocada final en John Cameron Mitchell, pues Mitchell instruirá a los (ya no lectores sino) espectadores modernos. Es una relación compleja, variada y entretejida de discípulos y maestros, vale decir, es una tradición compuesta pero unificada.

Dicho lo anterior, podemos, ahora sí, fijar nuestra mirada en la trama dentro del guion y la película. ¿Cuántas relaciones de amor entre adultos y jóvenes encontramos en la película? Son variadas y distintas, pero son bastantes. Sin embargo, aquellas que poseen fines educativos tienen un giro específico, porque no solo se da entre Hedwig y Tommy, sino paralelamente entre Hedwig y Yitzhak.

Aunque relaciones tortuosas ambas, existe un punto diferencial entre estas: Hedwig genera una relación fructífera con Tommy, pero no con Yitzhak. Es como si Hedwig, herido otra vez por Eros en su separación con Tommy, fuera incapaz de reconocer la propia lección que se dio cuando fue abandonada por Luther:

6 John Cameron Mitchell, dir., Hedwig and the Angry Inch, Killer Films, 2001. 
"I put on some make-up. Turn up the eight track. I'm pulling the wig down from the shelf. Suddenly I'm this punk rock star of stage and screen. And I ain't never. I'm never turning back".

Comienza un viaje solitario para el personaje y, sin embargo, jamás (acaso hasta el final del filme) Hedwig tuvo tanta posesión de sí misma, en actitud, determinación y empuje propio. Primero autopoiesis y luego poiesis parece cantar como eco esta canción en voz de ella. Así pues, abandonada por Tommy, Hedwig se aleja de su propia lección. Es necesario hacer una pausa. Puede parecer cruel hacer responsable a Hedwig de este estancamiento, pues $¿$ no es mucho el hecho de haber sido abandonada sumado al hecho de que fue robada en su creación artística, la marca precisamente de esta autopoiesis? ¿Cómo no ser presa de la desesperación y la confusión?

Llegados a este punto es necesario entender que Hedwig no sigue a Tommy para obtener pruebas en su demanda legal sobre la autoría de las canciones. Hedwig (otra vez) no sabe quién es, pero esta vez no tiene fuerzas para sacar el jugo de una de las enseñanzas más elevadas que Diótima dijo a Sócrates: el amor es, en últimas instancias, procreación en y por la belleza. Esto explicaría la relación que mantiene con Yitzhak totalmente infértil. Al inicio de la película, un beso entre ellos se verá interrumpido cuando desde la televisión se escucha la voz de Tommy. Hedwig se enfurece y rechaza con fuerza la muestra de cariño de Yitzhak; luego este patea una peluca y dice que Hedwig debería escribir canciones nuevas. Aunque son pocos los momentos, la película otorga momentos realmente poderosos a este personaje. Su relación con la peluca (tensión y tentación) nos indica que posee su propio viaje solitario y, sin embargo, su maestra está decaída, ya no posee algo qué darle; en consecuencia, él tampoco. La historia entre ellos es diametralmente opuesta a la que hay con Tommy. Solo cuando Hedwig se recupera a sí misma, es cuando Tommy como Yitzhak pueden cumplir esta función virtuosa entre maestro y discípulo. Al final de la película, Tommy desaparece de la vista de Hedwig, pero es Yitzhak quien tiene su momento de reconstitución: la peluca (símbolo de performatividad identitaria, de género y sexual) reinserta a Yitzhak en la sociedad, tanto como ciudadana (pues recordemos cómo Hedwig rompe su pasaporte) como ser sexuado.

Llegado este punto, demostrar que la tesis sobre el amor expuesta por Diótima se superpone a la trama del filme, requiere entender esta tensión vertical sutilmente expuesta por la trama. La visión de la belleza en sí es un devenir constante, no posee una etapa final, y a mayor altura mayor es el peligro de caer, y difícil volver a subir. Acaso Diótima ha dicho a Sócrates otra lección en la lección, una lección en que le pide que si puede debe seguir su ritmo, porque solo existe un seguir continuo, y ante tal velocidad (casi absoluta), incluso, Sócrates debió ser aprendiz.

\section{El discurso de Diótima sobre el amor y el amor como creación para Hedwig}

George Steiner hace una revisión a toda una tradición occidental que plantea disputas, encuentros, reencuentros y rupturas entre maestros y discípulos. En un apartado específico, casi todo dedicado al padre de la mayéutica, zanja el brillo especial que tiene Sócrates para Platón y para Alcibíades:

7 Mitchel, Hedwig and the Angry Inch. 
Sócrates es, valiéndonos de un término poco elegante, un "erotista”. La naturaleza, la cualidad del amor, desde la lascivia hasta la trascendencia (agapé), llena sus indagaciones. El control y el despliegue del eros dentro de lo político, dentro del alma individual, la concordia y el conflicto entre el amor y la búsqueda filosófica de verdades primordiales -estas dos últimas cosas, a la postre, han de ser unificadas-, son un tema recurrente en el Sócrates platónico. A través del neoplatonismo y del cristianismo helenizado, el eros socrático-platónico impregnará el pensamiento y la sensibilidad occidentales. En realidad, el amor socrático es homoerótico. ${ }^{8}$

El detalle estriba en la completa posesión que tiene un maestro ante el discipulazgo. Acaso todas las tradiciones en la historia de la humanidad no sean sino obra de ciertos maestros anónimos, como lo sugiere el propio Steiner. Esto se da, nos dice Steiner, gracias a que el maestro es un ejemplo vivo de lo que enseñanza. El planteamiento de Platón sugiere eso en todas las apologías y en todos los elogios en que el centro de gravedad es Sócrates. Pero esto es posible gracias a Diótima, no tanto por su estatus (otra vez) de maestra, sino por su capacidad de alzar a Sócrates rumbo a esa tensión hacia las profundidades o lo vertical de la que hemos hablado.

Diótima hace con Sócrates lo que Sócrates hace con los demás: evidencia su ignorancia en el tema del amor, pero lo más escandaloso es que sitúa el núcleo de la verdad en una aporía. Guthrie muestra una desavenencia con el también erudito Reginald Hackforth, pues para este el pasaje que se muestra a continuación mantendría un escepticismo en el corpus platónico de la teoría de la inmortalidad del alma:

De esta manera, en efecto, se conserva todo lo mortal, no por ser siempre completamente lo mismo, como lo divino, sino porque lo que se marcha y está ya envejecido deja en su lugar otra cosa nueva semejante a lo que era. Por este procedimiento, Sócrates -dijo-, lo mortal participa de inmortalidad, tanto el cuerpo como todo lo demás; lo inmortal, en cambio, participa de otra manera. No te extrañes, pues, si todo ser estima por naturaleza a su propio vástago, pues por causa de inmortalidad ese celo y ese amor acompaña a todo ser. ${ }^{9}$

Sócrates vuelve a preguntar a Diótima si esto es así, a lo cual la sacerdotisa responde que el filósofo ha de reparar en los terribles estados y esfuerzos que acometen los hombres para alcanzar distintos estados de inmortalidad (inmovilidad-divinidad). Acaso la sección más recordada sea aquella campanada final donde Diótima termina su discurso a Sócrates:

¿O no crees - dijo- que solo entonces, cuando vea la belleza con lo que es visible, le será posible engendrar, no ya imágenes de virtud al no estar en contacto con una imagen, sino virtudes verdaderas, ya que está en contacto con la verdad? Y al que ha engendrado y criado una virtud verdadera. ¿ No crees que le es posible hacerse amigo de los dioses y llegar a ser, si algún otro hombre puede serlo, inmortal también él? Esto, Fedro, y demás amigos, dijo Diótima y yo quedé convencido; y convencido intento también persuadir a los demás de que para adquirir esta posesión difícilmente podría uno tomar un colaborador de la naturaleza humana mejor que Eros. ${ }^{10}$

8 George Steiner, Lecciones de los maestros (Madrid: Siruela, 2005), 21.

9 William Keith Chambers Guthrie, Historia de la filosofía griega (Madrid: Gredos, 1990), 257.

10 Guthrie, Historia de la filosofía griega, 265. 
¿Hasta donde llega la ironía de Sócrates o Platón respecto del hecho de convertir a Sócrates en un discípulo apenas apto para captar la veloz dialéctica de la extranjera de Mantinea? Allende los límites circunscritos en esta pregunta, es innegable que el papel de la sacerdotisa es precisamente el de una mujer practicante. La ejecución continua acaso haya llegado a Sócrates (y Platón) como el núcleo más recóndito de su discurso. Bajo esta lectura, la apología en El banquete no sería tanto de Sócrates como de la vida del filósofo: Platón y Sócrates a la vez. La disputa (otro agón) entre Guthrie y Hackforth podría tener una alternativa, la palabra clave sería el hábito, la práctica. ¿Por qué escoger este enfoque? Guthrie lo dice explícitamente ("El problema puede ser insoluble") hablando del pasaje más enigmático de todo el discurso:

Un hombre mantiene su identidad a lo largo de su vida, aunque no solo está deteriorándose y renovándose constantemente en su cuerpo (como dijo Cebes en el Fedón 87d), sino que, incluso en su personalidad ( $p s y c h e ́)$, su carácter, hábitos, opiniones, deseos, placeres, dolores y temores, nunca permanece el mismo. Más sorprendente todavía (como lo llama Diótima y algunos pueden conceder), en nuestro conocimiento tampoco somos nunca los mismos. Los contenidos del conocimiento vienen y van: los perdemos por el olvido y los recuperamos por el recuerdo. ${ }^{11}$

Siguiendo a Hackforth, ¿hay que pensar en Platón como un cuerpo unitario de doctrinas cerradas, carentes de elementos que complejicen una posición y su red de conceptos? Es decir, ¿está Platón exento de escepticismo, de agón mismo en relación con Sócrates-Diótima? ¿O incluso consigo mismo? Acaso la vitalidad de los Diálogos consista en esta suma, que, al final de cuentas, es la vida del filósofo, su práctica continua en una escalada sin aparente fin. Es Peter Sloterdijk quien probablemente haya rescatado esta vertiente para la filosofía contemporánea, cuyo concepto de la antropotécnica merece plena atención en este sentido:

Los filósofos primitivos, los primeros gurús y pedagogos atienden cada vez más, en el albor de su arte, al segundo frente, a esa vertiente de "animal de costumbres" de la condición humana. Se podría hablar aquí de las formas habituales o héxicas (del latín habitus, "hábito" "Costumbre", y del griego héxis, "manera de ser", "estado" o "hábito" corporal, "estado" o "hábito" anílnico), de la "posesión". Una vertiente que representa la "posesión" como "posesión" por parte de algo que no es espíritu, sino un mecanismo corporeizado. ${ }^{12}$

La trama de Hedwig and the Angry Inch posee esta tensión no solo como el efecto de anagórisis para Hedwig (más adelante tocará repasar la relación con Tommy Gnosis); la Hedwig que se presenta la película, en sus constantes alusiones al Muro de Berlín, sus repetidas acepciones como un ser "entre" o "en medio" son solo los restos de una lejana autopoiesis; cuando comienza la película no son una práctica, son mera ideología que encubre su derrota para reconstruirse de nuevo. Otra vez hay que pensar en John Cameron Mitchell: ¿cuál es el primer plano que maneja la película, no su fondo, sino la presentación de las condiciones que impulsan a Hedwig a hacer un repaso de su vida? Sería un muy mal filme si la respuesta fuera: porque así hace avanzar el argumento. Por el contrario, Hedwig necesita repasar toda su existencia, lo que ha aprendido, olvidado, lo que ha sido y lo que es, lo que crees que es y lo que quiere o no quiere ser. Está en otro momento umbral, su primera canción (que se nos presenta en la película); en ese sentido, no se equivoca: es un muro, pero también un puente. El detalle es que ahí carece, en el

11 Guthrie, Historia de la filosofía griega, 376.

12 Peter Sloterdijk, Has de cambiar tu vida, trad. por Pedro Madrigal (Valencia: Pre-Textos, 2012), 222. 
mismo inicio del filme, de este y de oeste; de orillas. Sloterdijk le diría (como a todos nosotros): "Has de cambiar tu vida”.

Bajo estas condiciones, Hedwig opera como un maestro envejecido, cansado (acaso esto no sea otra cosa que la figura de los críticos y los comentadores), ajeno a eros. Pero esto es resultado del primer plano que tiene la película: Hedwig no escribe más, no crea más. Ha caído bajo la fascinación de Tommy; acaso las pruebas son cada vez más complicadas y complejas conforme hemos estado (o creído estar) cercanos a la visión absoluta del amor, el cual, como dijo Diótima, es amor a la generación y procreación en lo bello. El núcleo realmente incómodo de la enseñanza de Diótima es el mismo núcleo olvidado o rechazado por Hedwig:

Pues lo que se llama practicar existe porque el conocimiento sale de nosotros, ya que el olvido es la salida de un conocimiento, mientras que la práctica, por el contrario, al implantar un nuevo recuerdo en lugar del que se marcha, mantiene el conocimiento, hasta el punto de que parece que es el mismo. ${ }^{13}$

Sí, la película toca las fibras de la identidad, pero no cae en el lugar común de tratarla bajo la óptica fácil del género. Muy al contrario, la identidad está problematizada más allá del discurso de Aristófanes en El banquete. Parece ser una verdad de Perogrullo, pero podemos olvidar (cómo no tratando estos temas) que John Cameron Mitchell no es Hansel-Hedwig. La película no tiene su agón con el discurso de Aristófanes (el cual es, quizá, el elemento más popularizado y extendido de la enseñanza de Platón), sino con el de Diótima/Sócrates. Hedwig debe salir de sus propios nudos a través de lo que ya sabía: la creación. La contradicción de Hedwig, de nuevo, va más allá de sus genitales y de su género; ha olvidado, no es más un ejemplo vivo, un practicante, no es más un hábito. La aventura solitaria es esa: ha de reencontrarlo, sola, completamente sola. Y, sin embargo, ¿qué es esta relación maestro-discípulo? ¿De dónde aprendió Diótima?

\section{Anagnórisis a través de Tommy Gnosis}

La respuesta a la pregunta con la que concluye el apartado anterior fue dada desde un inicio. Y por ello la pregunta es concluyente. De igual manera, Hedwig misma podría ser Diótima, sacerdotisa del rock (y de hecho, así es como concluye el argumento, se reencuentra como cantante, escribe de nuevo y recuerda a otras practicantes del rock: "Here's to Patti / And Tina / And Yoko / Aretha / And Nona / And Nico / And me / And all the strange rock and rollers / You know you're doing all right / So hold on to each other / You gotta hold on tonight"). ${ }^{14}$ El hábito practicante del rock regresa y el error que hay que evitar es suponer que primero se reencuentra como un ser completo y luego regresa al núcleo de la creación. El proceso en El banquete hace de los filósofos precisamente aquellos quienes engendran y crían la virtud verdadera; es decir, quienes están (precisamente) poseídos por el demon o daimón Eros.

13 Platón, Diálogos, 257.

14 Mitchel, Hedwig and the Angry Inch. 
¿Cómo se desanuda pues la tensión y el agón entre Tommy y Hedwig? Primero, es menester considerar los momentos de real cruce entre los personajes. El primer momento en la bañera no es solo anecdótico, funciona como un correlato a lo establecido por los comensales del banquete en el texto de Platón. La fascinación del cuerpo joven y bello como punto de entrada. ¿Pero en el caso de Tommy? ¿Qué lo hace ir a ver a Hedwig un poco de incógnito?

La respuesta está dentro de Tommy, pero nosotros como espectadores lo sabremos hasta que el propio chico cuente su lectura e interpretación del relato bíblico entre Adán y Eva. Es decir, Hedwig escucha algo en la voz de Tommy que lo hace recordar su propio y antiguo ser: alguien, ciertamente ingenuo, pero que posee un empuje. En otras palabras, se reconocen. La relación erótica se suscita como todo un proceso que a la vez se sustenta en lo que dice Tommy: "You know what He saved us from was his fucking father. I mean, what kind of God creates Adam in his image, pulls Eve out of him to keep him company, and then tells them not to eat from the Tree of Knowledge? [...] Eve just wanted to know shit". ${ }^{15}$

En otras palabras, Eva necesita recordar. Esto nos muestra a Tommy como un practicante, joven, ciertamente muy joven, pero existe esta dimensión. Hedwig recibe su propio mensaje, pero a la inversa. ¿Cómo y dónde empieza la posesión de eros? Tommy ya está poseído por el impulso creador; pequeños diálogos nos dejan entrever que su propia lectura del mito adánico es una defensa ante su padre. En pocas palabras, Tommy es como Hedwig fue en sus inicios: ha recurrido a su propia interioridad para detectar dónde se hallan los (verdaderos) maestros. La entrega de la manzana que pide a Hedwig posee un valor semántico múltiple; es obvio que hay una entrega erótica, pero, por obvias razones, también involucra una dimensión pedagógica. Lo interesante es cómo se crea una ambivalencia que bien vista es muy ilustradora. ¿Quién le otorga la manzana a quién?

El punto a destacar es precisar el momento en que este encuentro es posible: Hedwig está en la faceta mendigante de Eros. Ebria, en medio de un basurero, sin casa, cuenta a unos desconocidos toda su historia con Tommy. De nuevo, hay que pensar en la disposición de esta escena: Diótima comenta que Eros, en tanto intermediario entre hombres y dioses (lo móvil y lo inmóvil), es "siempre pobre, y lejos de ser delicado y bello, como cree la mayoría, es, más bien duro y seco, descalzo y sin casa", ${ }^{16}$ descripción que calza a la perfección con el Hedwig que cuenta su historia en el basurero. Y, sin embargo, Hedwig siempre ha sido eso, nunca ha tenido una casa, siempre ha estado descalzo en más de un sentido (¿no es el desamparo un motivo recurrente en la presentación de Hedwig?). Ya se ha insistido en el hecho de que, una vez abandonada por Luther, Hediwg convierte su casa (un remolque, dicho sea de paso, que agrega de nuevo la idea de un ser en devenir) en un escenario. No es solo un aparato teatral que se agrega desde lo exterior (el director de escena, por ejemplo); como espectadores, en ese momento, asistimos a la transformación de su propio espacio interior, la casa será el escenario, el único lugar donde está realmente en casa. Y, precisamente, en ese instante es cuando Hedwig también cumple con la otra faceta de Eros en boca de Diótima: "está al acecho de lo bello y de lo bueno; es valiente, audaz y activo, hábil cazador, siempre urdiendo alguna trama, ávido de sabiduría y rico en recursos, un amante del conocimiento a lo largo de toda su vida, un formidable mago, hechicero y sofista”. ${ }^{17}$ Hedwig, a pesar de estar destrozada por

15 Mitchell, Hedwig and the Angry Inch.

16 Platón, Diálogos, 249.

17 Platón, Diálogos, 249. 
las circunstancias, crea, primero, hacia dentro y, luego, hacia afuera. ¿Cuál es el resultado de ese intenso umbral que ha cruzado? Es la canción que canta cuando Tommy la sigue la primera vez. Invariablemente, sería un error pasar por alto el siguiente diálogo de Hedwig en uno de sus momentos de mayor posesión de sí misma: "This is actually, the first song I’ve ever written. And it’s written for a guy to sing". ${ }^{18}$

La canción de la que habla es Wicked Little Town. Y es evidente que se trata de una despedida, no solo de un pueblo, sino de un locus interno, un estado. Pero más allá de esto, ¿por qué está escrita para ser cantada por un joven? Muchos han querido entender este momento como una muestra de su confusión en materia de género. Más allá de afirmar o negar esto, se busca agregar una escala más honda a esta discusión. El lector que haya llegado hasta aquí siguiendo la argumentación sabrá que hemos regresado al tema de la anamnesis como anagnórisis, porque, ¿y si está pensada para ser cantada por el joven que no pudo ser (Hansel), no tanto en materia de género, sino en tanto hubo un chico apasionado del rock y discípulo poseído por Eros, que luego fue amputado violentamente de esta aventura? Es decir, ¿por qué no está escrita para que la cante Hedwig y, no obstante, Hedwig la canta de modo que es allí donde Tommy alcanza la posesión de sí mismo como practicante (del rock)?

El agregado de complejidad netamente moderno, que se superpone al discurso de Platón, gracias al filme, tiene su punto nodal en este instante desarrollado hacia atrás y hacia adelante. Hacia atrás en tanto la construcción de una práctica: la creación y sus entresijos. Hacia adelante en tanto recuperación de una práctica: la creación y su aventura solitaria. Y esto se cruza con el final de la película cuando Hedwig recibe una reconstrucción de su propia creación: Wicked Little Town es el campo de batalla donde los discursos sobre el amor de Tommy Gnosis y Hedwig tienen lugar, pero singularmente también donde anida la incómoda lección de Diótima que será reapropiada por ambos.

Se ha llegado a este punto desde que se tomó el hilo conductor de Tommy como un practicante del rock, no por su condición manceba o novata en este mundo, sino por su apropiación del mito del árbol de conocimiento; vale decir, su momento autopoiético. Esta recreación será casi culminada cuando más adelante en el discurso de Hedwig se nos relate cómo fue el rompimiento entre ambos. Bautizado aquí como Tommy Gnosis (puesto que Hedwig le hace heredero de su conocimiento -¿de nuevo, quién le dio la manzana a quién?-) un momento de tensión erótica llega a punto culminante en su discurso: "Oh, God, oh, Hedwig, when Eve was still inside Adam, they were in paradise. [...] When she was separated from him, that's when paradise was lost. So when she enters him again, paradise will be regained" ${ }^{19}$ Pero, como es bien sabido, este momento sumamente teatralizado (muy parecido a cuando la casa de Hedwig se metamorfosea en escenario) se derrumba cuando Tommy siente los genitales mutilados de Hedwig. Uno está muy tentado de reconocer aquí un toque de fina ironía como comentario a la filosofía platónica: basta una pulgada furiosa de realidad para derribar todo su sistema. El detalle estriba en que Mitchell ve eso, no como una incompletud, un hueco que deba ser saturado o una confusión que deba solventarse, sino que ve allí un potencial creativo...

Finalmente, la escena más revisada y que más efecto patético genera es aquella en la que se reencuentran Hedwig y Tommy en una puesta en escena muy peculiar. Este trabajo insiste mucho en la teatralidad de las escenas y sus montajes (no olvidemos que en su origen se trata de un musical y el filme no lo olvida,

18 Mitchell, Hedwig and the Angry Inch.

19 Mitchell, Hedwig and the Angry Inch. 
al contrario, todo está dirigido a completar un elogio a la forma del musical), porque acaso puedan comunicar mucho más que la obvia presencia de los personajes y sus existencias físicas en el mundo de su ficción: de la misma manera que Platón nos plantea un diálogo sumamente teatralizado. Y si de un efecto teatralizado se trata, el final de El banquete hace de Alcibíades un personaje singular. La disposición de los elementos entre este y el final del filme tiene puntos de encuentros y de separación. Hedwig está cansado de ser burlado por Tommy Gnosis (como Alcibíades por Sócrates); en el fondo, no busca el reconocimiento o los aplausos, su última presentación es la más violenta, no ya hacia el escenario donde canta y sus espectadores sino hacia dentro (como otras tantas estrellas del rock). Esta vez se despojará de sus avatares, sus accesorios y del propio escenario.

La situación umbral no puede ser más obvia. ¿Por qué no hay público en el concierto de Tommy Gnosis? Claramente, se trata de un momento que es solo y solo para Hedwig; por última vez entramos al espacio interior de Hedwig, ese lugar donde la autopoiesis se provoca, donde Eros tomará posesión (vale decir, toma lugar), de modo que pueda continuar procreando en lo bello. En su último concierto (en el que canta Midnight Radio), tiene la marca que puso a su discípulo y amante, la "gnosis" que perdió en un momento determinado. La tensión vertical que Diótima hace evidente cuando determina el amor como una secuencia de escalas (o escalones) hacia la contemplación de la idea tiene algo de inexorable: la identidad es y no es solitaria. Eros es el tertium non datur de esta ecuación. Solo bajo esta perspectiva Hedwig se reapropia de sí, no ya desde un género como identidad, sino como un practicante que mantiene el conocimiento "hasta el punto de que parece que es el [él] mismo": ${ }^{20}$ no solo cantante sino también compositor de rock and roll. Estableciendo un agón propio con Mitchell, sí, Hedwig es "mucho más que una mujer o un hombre”, pero no por su posición en el género, sino por su práctica, su poiesis.

\section{Conclusiones}

Es Octavio Paz quien genera la última lección: en La llama doble, específicamente en el capítulo dedicado a "Eros y Psiquis", nos dice lo siguiente:

Para Platón el amor no es propiamente una relación: es una aventura solitaria. Al leer ciertas frases de $E l$ banquete es imposible no pensar, a pesar de la sublimidad de los conceptos, en un Don Juan filosófico. La diferencia es que la carrera del Burlador es hacia abajo y termina en el infierno mientras que la del amante platónico culmina en la contemplación de la idea. Don Juan es subversivo y, más que el amor a las mujeres, lo inspira el orgullo, la tentación de desafiar a Dios. Es la imagen invertida del Eros platónico. ${ }^{21}$

La imagen es elegante y desafiante a la vez, pero, llegados a este punto, ¿no es Hedwig una imagen mucho más invertida del platonismo? Para sugerir una respuesta, hemos de formular una última pregunta relativa al filme. ¿Por qué Hedwig queda solo, desnudo en una ciudad caminando hacia la oscuridad? ¿No desaparece de manera parecida a la de Tommy Gnosis, apenas unos cuantos minutos atrás dentro del metraje? Se van porque han dicho lo que tenía que decirse y decirnos. Sí, el amor es una aventura

20 Platón, Diálogos, 257.

21 Octavio Paz, La llama doble (Barcelona: Seix Barral, 2014), 46. 
solitaria y, por eso, mismo es una relación. Por esto, la anagnórisis es anamnesis, la dialéctica es un agón y la identidad un devenir: ese sería el núcleo de la revisión moderna en voz de John Cameron Mitchell.

\section{Bibliografía}

Carrillo Osorio, Laura Alejandra. "El discurso de Pausanias en El banquete y la discontinuidad argumentativa entre Eros, pederastia y sociedad”. Saga: Revista de Estudiantes de Filosofía 15, no. 27 (2016): 28-35. https://revistas. unal.edu.co/index.php/saga/article/view/55777.

Gilabert Barberà, Pau. "Hedwig and the Angry Inch: El Platón más alternativo". Actas del XI Congreso Español de Estudios Clásicos 3 (2005): 679-690. http://diposit.ub.edu/dspace/handle/2445/12165

Guthrie, William Keith Chambers. Historia de la filosofía griega. Vol. 4: Platón, el hombre y sus diálogos: Primera época. Madrid: Gredos, 1990.

Heidegger, Martin. "La época de la imagen del mundo". En Caminos de bosque. Madrid: Alianza, 1996. http://www. fadu.edu.uy/estetica-diseno-i/files/2015/08/heidegger_epoca_imagen_mundo.pdf

Mitchell, John Cameron, dir. Hedwig and the Angry Inch. Killer Films, 2001.

Paz, Octavio. La llama doble. Barcelona: Seix Barral, 2014.

Platón. Diálogos. Traducido por Carlos García Gual, Marcos Martínez Hernández y Emilio Lledó Íñigo. Madrid: Gredos, 1986.

Sloterdijk, Peter. Has de cambiar tu vida. Traducido por Pedro Madrigal. Valencia: Pre-Textos, 2012.

Steiner, George. Lecciones de los maestros. Madrid: Siruela, 2005. 